\title{
STOICHIOMETRIC CHARACTERISTICS AND DRIVING MECHANISMS OF PLANTS IN KARST AREAS OF ROCKY DESERTIFICATION OF SOUTHERN CHINA
}

\author{
ZHANG, Y. - XIONG, K. N. ${ }^{*}$ - YU, Y. H. - YANG, S. - LIU, H. Y. \\ School of Karst Science, Guizhou Normal University/State Engineering Technology Institute for \\ Karst Desertification Control, No. 116 Baoshan North Road, Yunyan District, Guiyang City, \\ Guizhou Province 550001, China \\ *Corresponding author \\ e-mail: hxcandzy@163.com
}

(Received 20 $0^{\text {th }}$ Nov 2019; accepted $12^{\text {th }}$ Feb 2020)

\begin{abstract}
In this study, we selected karst areas of rocky desertification in southern China as a subject analyze the nutrient transport patterns of the plant-litter-soil continuum and the effect of soil environmental factors on plant stoichiometry in two areas: potential-mild and moderate-severe rocky desertification. The results show that (1) the carbon $(\mathrm{C})$, nitrogen $(\mathrm{N})$, and phosphorus $(\mathrm{P})$ contents of plant leaves in karst areas are higher than those of litter or soil; (2) the plant leaves have a high C storage capacity, P sufficiency, and N deficiency; and (3) the Monte Carlo test of eight soil environmental factors showed that the influences of soil environmental factors on plant stoichiometry vary with the level of rocky desertification. In the area of potential-mild rocky desertification, soil $\mathrm{pH}, \mathrm{TP}, \mathrm{C}: \mathrm{P}$, and SOC were the main driving factors. In the area of moderate-severe rocky desertification, soil TP, TP, C:N, and SWC were the primary driving factors. The comprehensive analysis can provide a theoretical basis for nutrient transport and soil environmental factor regulation in areas with different levels of rocky desertification. It is necessary to target the primary factors for fertilization management and nutrient transport protection in future rock desertification control.
\end{abstract}

Keywords: ecosystem, rocky desertification degree, nutrient cycling, environmental factor

\section{Introduction}

The karst region in southern China, centered in Guizhou, is one of the three continuous karst distribution centers in the world and one of China's four ecologically fragile areas, making it the nation's key ecological development hinterland and poverty alleviation core area (LeGrand, 1973; Sheng et al., 2015; Wang et al., 2016a; Wang et al., 2016b). The karst rocky desertification ecosystem has low environmental capacity and poor anti-interference ability and is thus vulnerable to disruptions in ecological security and regional economic and social development (Xiong et al., 2016). Since the 1990s, a large number of vegetation restoration projects have been carried out in the region to promote the comprehensive management of rocky desertification, but the artificial vegetation ecosystem constructed is monotonous in structure and poor in stability, making it ill equipped to mitigate the ecological problems caused by the ecological environment with its shallow and noncontinuous soil layer and poor water conservation capacity (Zeng et al., 2015). Under intensive interference by human activities, natural secondary forests dominated by viny and thorny shrubs and scrubgrassland were formed (Zhong et al., 2018). Therefore, vegetation restoration and reconstruction are a necessary measure for the control of karst rock desertification.

Ecological stoichiometry is a discipline that studies the balance between important elements, such as carbon $(\mathrm{C})$, nitrogen $(\mathrm{N})$, and phosphorus $(\mathrm{P})$, in ecosystem interactions (Zhao et al., 2019). Plant stoichiometric characteristics can characterize the plant's ability 
to maintain internal stoichiometric stability while reflecting its adaptability to environmental changes (Sterner and Elser, 2002; Elser et al., 2010). In this way, they can provide the basis for the equilibriums of energy and chemical elements of the ecosystem as well as the structure and function of the ecosystem and soil nutritional diagnosis (Elser et al., 2000; Zhao et al., 2016). In the past, the characterization of stoichiometric characteristics has been focused on individual components of the ecosystem (e.g., soil, vegetation, or litter) or plant organs (plant leaves or fine roots, etc.) (Pena-Claros, 2003; Wu et al., 2010; Wang et al., 2011). Some other studies only examined the differences in stoichiometric characteristics and their intraspecies variation in different succession stages and during seasonal changes. These studies demonstrated that the stoichiometric characteristics of $\mathrm{C}, \mathrm{N}$, and $\mathrm{P}$ of plant leaves vary with vegetation type, functional group, and species (Sterner and Elser, 2002; Agren, 2004; Reich, 2003), but they rarely addressed the comprehensive situation of the community composed of trees, shrubs, and grasses and thus failed to integrate ecosystem components or comprehensively characterize the stoichiometric characteristics by taking into account environmental factors (Hu et al., 2014; Cao et al., 2015).

Soil is an important factor of terrestrial ecosystems (Gusewell, 2004). To examine the variation characteristics of nutrient elements, it is necessary to thoroughly investigate the conversions between the nutrient return from litter decomposition, soil nutrient supply, and plant nutrient demand in different environments (Xiang et al., 2015). Soil environmental factors not only provide plant nutrients but also catalyze and regulate the process of litter decomposition, thereby sensitively reflecting the direction and intensity of the driving mechanism of nutrients in different karst areas of rocky desertification. Currently, the nutrient element transfer and its regulation mechanism in karst areas with different levels of rocky desertification have rarely been addressed, and there has been no study on the soil environmental factors that drive the plant stoichiometry (including leaf stoichiometry and litter stoichiometry), making it difficult to systematically reveal the coupling mechanism between plants and the environment. Therefore, it is necessary to conduct an in-depth stoichiometric study that takes plants and soil as a whole (Du et al., 2016, 2017).

In this study, our aims were to: (1) examined vegetation, litter, and soil as a whole system and investigated the stoichiometric characteristics of karst areas. (2) Describe the elemental circulation and balance mechanism of the soil-litter-vegetation continuum in environments with different levels of rocky desertification. (3) Revealed the synergistic driving effect of soil environmental factors on the stoichiometric characteristics of plant leaves and litter. Our findings are conducive to strengthening the management and protection of the ecological environment in areas of rocky desertification and provide a theoretical basis for the management of vegetation restoration and reconstruction in karst areas of rocky desertification.

\section{Materials and methods}

\section{Overview of the study area}

The Salaxi Rocky Desertification Comprehensive Management Demonstration Area of Bijie and the Guanling-Zhenfenghuajiang Rocky Desertification Comprehensive Management Demonstration Area (Fig. 1) are the two most representative areas of rocky desertification in Guizhou Province of southwest China, with diverse rocky desertification levels and typical rocky desertification status. These were selected as the 
study area. Both demonstration areas have been used as special study cases for the comprehensive control of rocky desertification of Guizhou Province from 1995 to 2019.

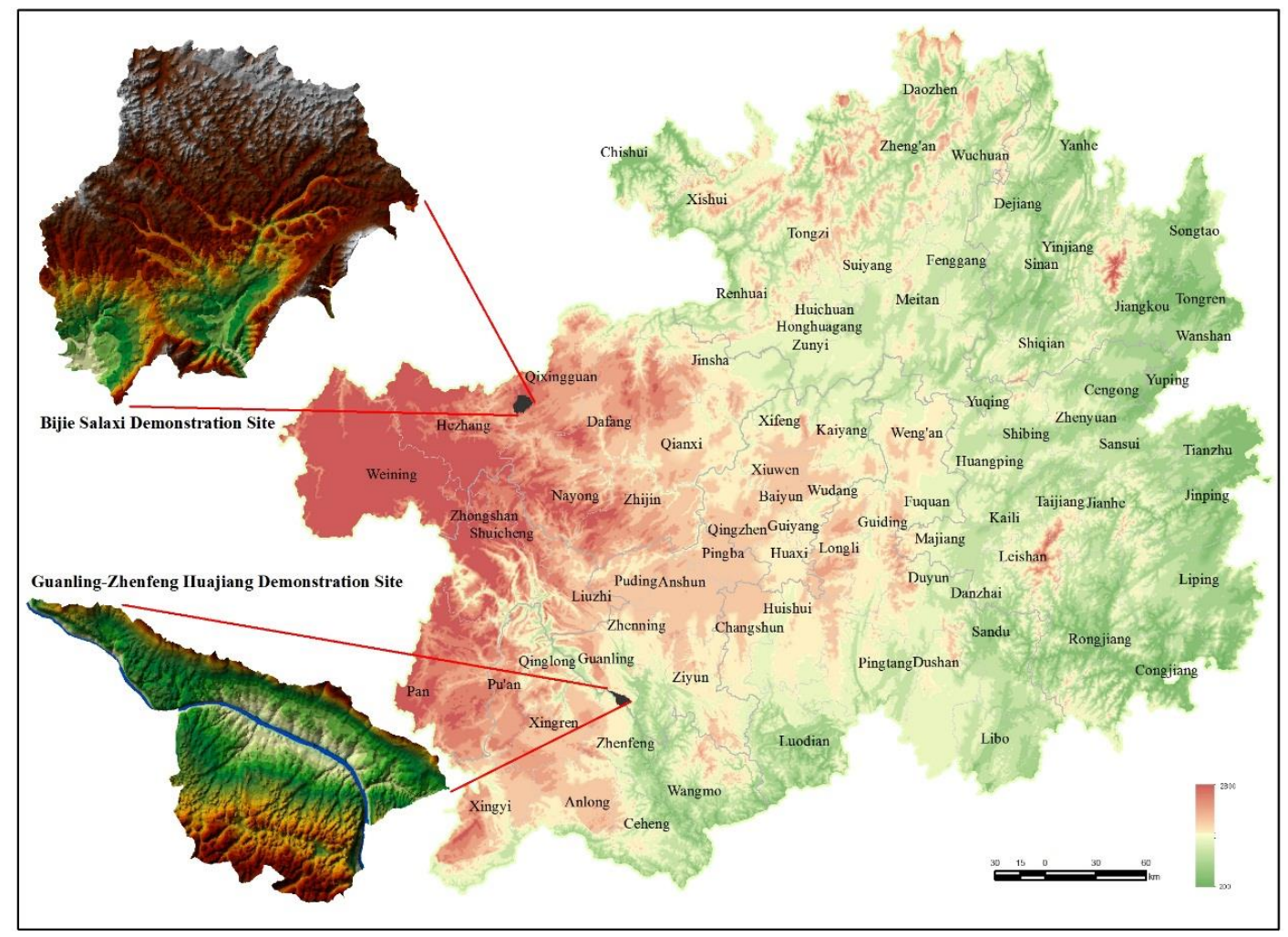

Figure 1. The location of the two demonstration areas in Guizhou Province

The Salaxi Rocky Desertification Comprehensive Management Demonstration Area of Bijie (Fig. 2), located in the northwest of Guizhou Province $\left(105^{\circ} 01^{\prime} 10^{\prime \prime}-105^{\circ} 08^{\prime} 39^{\prime \prime} \mathrm{E}\right.$, $27^{\circ} 11^{\prime} 08^{\prime \prime}-27^{\circ} 17^{\prime} 30^{\prime \prime} \mathrm{N}$ ) and the southwest of Bijie city, is within the tributary area of the Liuchong River Basin. It has a north subtropical humid monsoon climate (annual average temperature: $12{ }^{\circ} \mathrm{C}$; annual average precipitation: $984.40 \mathrm{~mm}$ ) and an altitude of 1,4952,200 $\mathrm{m}$ (relative height difference: $705 \mathrm{~m}$ ). The total size of the demonstration area is $86.27 \mathrm{~km}^{2}$, of which the karst area accounts for $73.94 \%$. The areas of potential, mild, moderate, and severe rock desertification account for $30.91 \%, 22.26 \%, 8.57 \%$, and $3.09 \%$ of the karst area, respectively. The soil is dominated by zonal yellow soil, with a small proportion of yellow-brown soil and weathered calcareous soil. The native vegetation was mostly destroyed and is now dominated by secondary forests, in which Pinus armandii, Pinus yunnanensis, Betula luminifera, Populus alba, and Quercus variabilis dominate the arborous layer; Pyracantha fortuneana, Rosa roxburghii, Cotoneaster franchetii, Hypericum chinense L., Rhododendron simsii, and Corylus heterophylla var. sutchuenensis dominate the shrub layer; and Trifolium repens, Lolium perenne, Dactylis glomerata L., Bromus catharticus, and Imperata cylindrica dominate the grassland.

The Guanling-Zhenfenghuajiang Desertification Comprehensive Management Demonstration Zone of Bijie (Fig. 3) is in the southwestern part of Guizhou Province $\left(105^{\circ} 36^{\prime} 30^{\prime \prime}-105^{\circ} 46^{\prime} 30^{\prime \prime} \mathrm{E}, 25^{\circ} 39^{\prime} 13^{\prime \prime}-25^{\circ} 41^{\prime} 00^{\prime \prime} \mathrm{N}\right)$ and the river banks of the Huajiang Valley of the Beipan River, which is to the south of Guanling County and the north of Zhenfeng County. It has a north subtropical monsoon climate (annual average 
temperature: $18.4{ }^{\circ} \mathrm{C}$; annual average precipitation: $1,100 \mathrm{~mm}$ ) and an altitude of 450 $1,450 \mathrm{~m}$ (relative height difference: $1,000 \mathrm{~m}$ ). The total area of the demonstration area is $51.62 \mathrm{~km}^{2}$, of which the karst area accounts for $87.92 \%$, and the areas of potential, mild, moderate, and severe rock desertification account for $24.54 \%, 40.48 \%, 17.93 \%$, and $17.06 \%$ of the total karst area, respectively. The soil is dominated by yellow soil and yellow calcareous soil. The natural vegetation in the area includes Cupressus funebris, Eucalyptus spp., Tectona grandis, Koelreuteria paniculata, and Cladrastis platycarpa (Maxim.) Makino in the arborous layer; Broussonetia papyrifera, Viburnum foetidum var. ceanothoides, Alchornea trewioides, and Rhus chinensis Mill. in the shrub layer; and Pennisetum hydridum, Lonicera japonica, Miscanthus sinensis, Arthraxon hispidus, and Imperata cylindrica in the grassland.

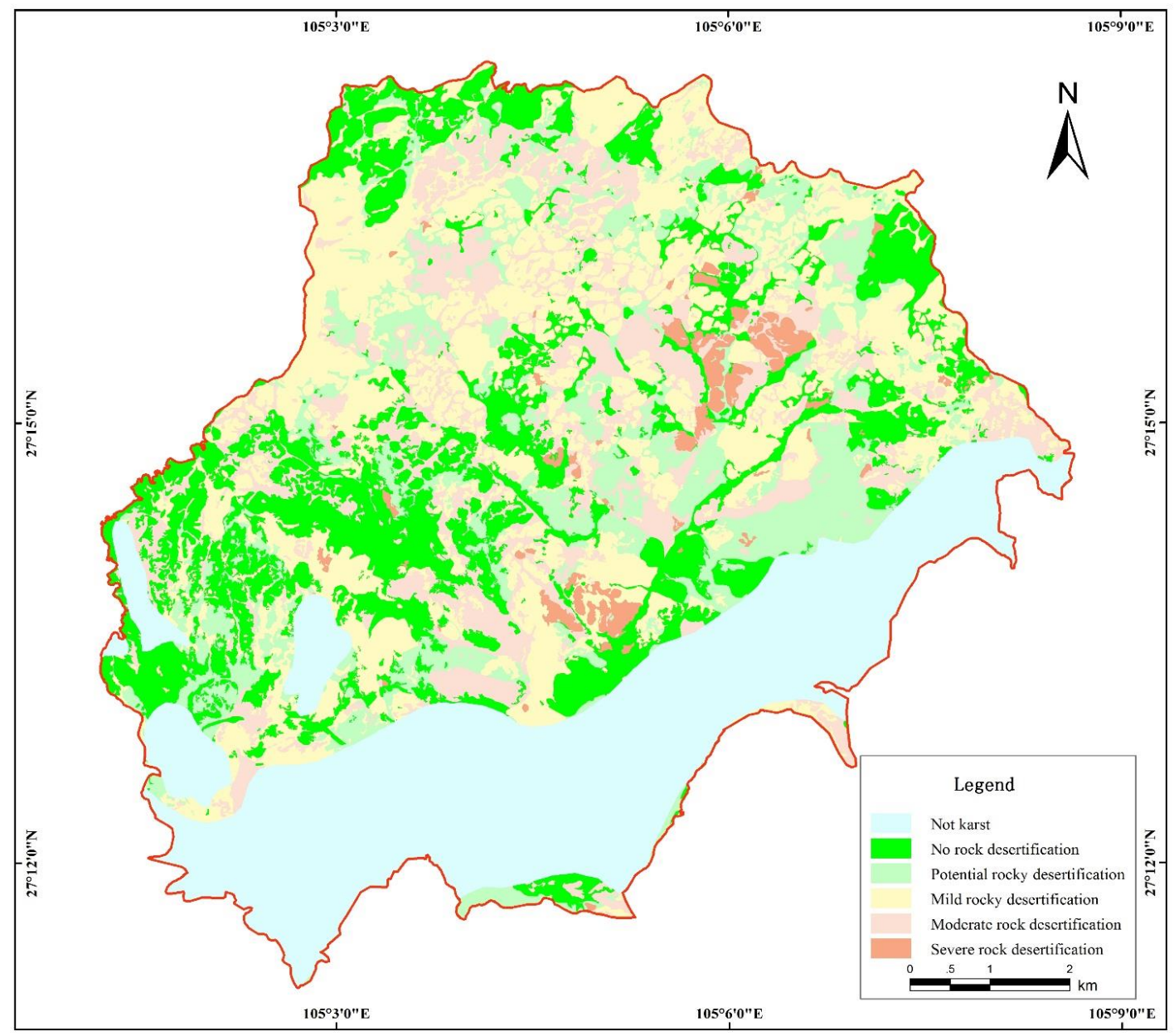

Figure 2. The Salaxi Rocky Desertification Comprehensive Management Demonstration Zone of Bijie

\section{Sample collection}

In the study area, the communities of trees, shrubs, and herbs with neat forests, uniform forest distribution, and similar average forest age were selected as subjects. In each demonstration area, 40 experimental plots were designed (80 in total in the two demonstration areas), including 27, 27, and 26 plots for trees, shrubs, and herbs, 
respectively, in which typical quadrats of $20 \mathrm{~m} \times 20 \mathrm{~m}$ were designed. The samples were collected in late August 2018, when plants were in the fast growth season. When collecting plant leaves, five to six healthy individual plants of the dominant species with similar vigor were randomly chosen from each quadrant, and healthy and mature leaves were collected from each of these plants facing four directions, i.e., east, west, south, and north, which were then mixed well and placed in a brown paper bag to be transferred to the laboratory. In each quadrant, approximately $350 \mathrm{~g}$ of each of dry, undecomposed, and semi-decomposed litter was collected from multiple spots. At each sampling site, soil samples were collected from the $0-20 \mathrm{~cm}$ soil depth (due to the shallow topsoil depth, in places with a topsoil depth shallower than $20 \mathrm{~cm}$, the samples were collected from the actual soil depth) in 3-4 root zones in an S-shaped sampling line and mixed, from which $1 \mathrm{~kg}$ was taken using the quartering method and brought back to the laboratory. Plant leaves and litter were baked in an oven at $65{ }^{\circ} \mathrm{C}$ to constant weight and then pulverized to powder $0.1 \mathrm{~mm}$ in size. The soil samples were air-dried, removed of impurities such as animal and plant residues and gravels, and then ground using an agate mortar and sieved through a 100-mm sieve. The sieved soil sample was placed in a plastic bag for analysis of soil chemical properties.

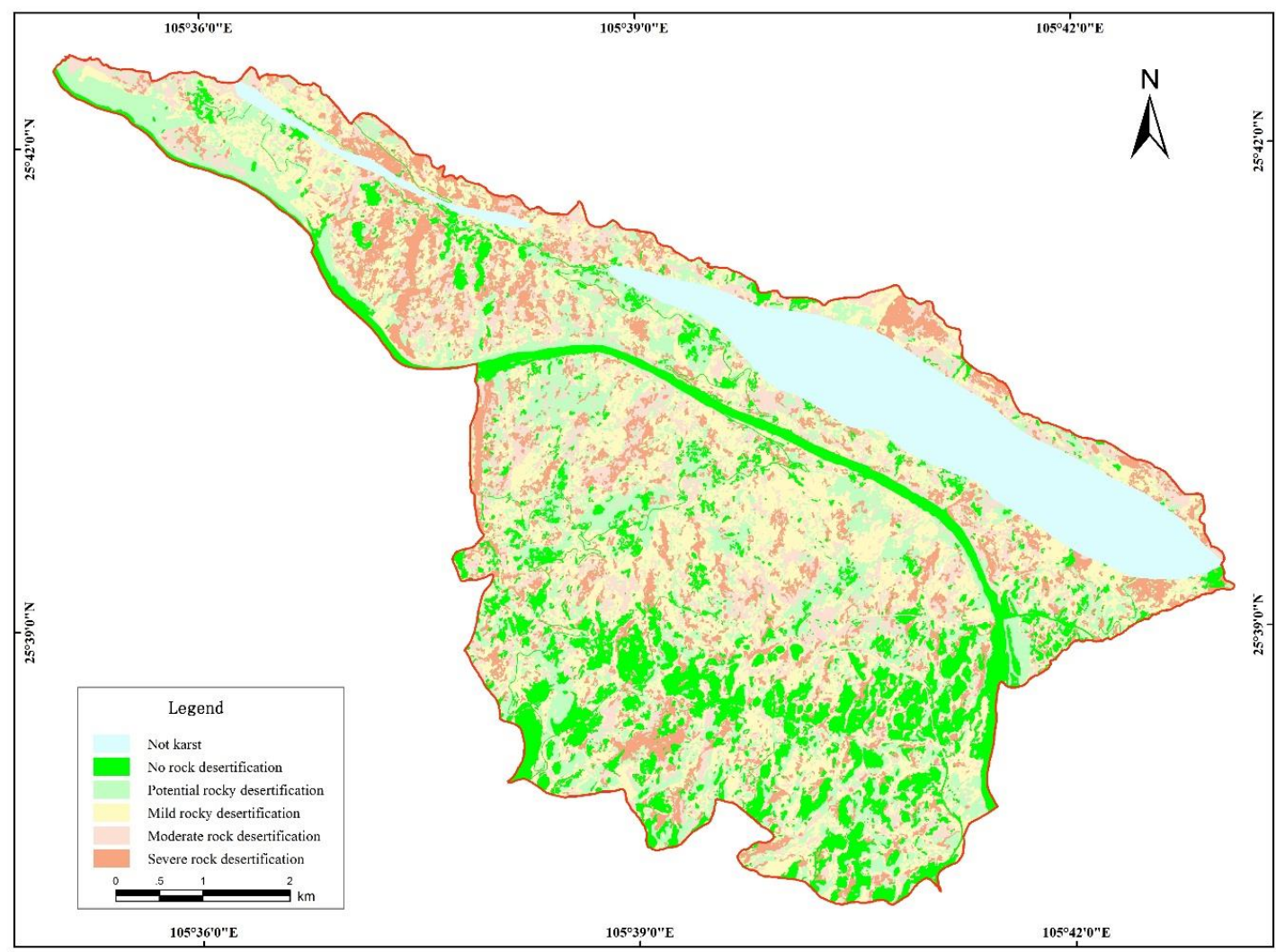

Figure 3. The Guanling-Zhenfenghuajiang Desertification Comprehensive Management Demonstration Zone

\section{Sample analysis}

The organic carbon (OC) contents of the leaf, litter, and soil were determined by oxidation with potassium dichromate under external heating, the total nitrogen (TN) 
contents using the semi-micro Kjeldahl method after heating in perchloric acid-sulphate acid, and the total phosphorus (TP) contents using Mo-Sb colorimetry-UV spectrophotometry after heating in perchloric acid and sulfuric acid. Soil $\mathrm{pH}$ was determined using a potentiometer in the soil solution (water: soil ratio $2.5: 1$ ). Soil water content (SWC) was determined using the cutting ring method.

\section{Data processing and statistical analysis}

The nutrient content data of plant leaf, litter, and root-zone soil were performed with one-way analysis of variance and regression analysis. The result of a data distribution test showed that the contents of $\mathrm{C}, \mathrm{N}$, and $\mathrm{P}$ of plant leaf, litter, and soil samples mostly assumed nonnormal distributions but were normally distributed after logarithmic transformation, so their log-transformed values were described with geometric means. The significance test of multiple comparisons was performed using the least significant difference method, and $P<0.05$ indicated that the difference was significant. The $\mathrm{C}: \mathrm{N}: \mathrm{P}$ comparison results were plotted using 3D Scatter software. The above-described statistical analyses of the data were performed within Origin 8.6 for Windows.

The soil $\mathrm{C}, \mathrm{N}$, and $\mathrm{P}$ contents of different sampling sites and their respective stoichiometric variation strengths were categorized into three levels (Eq. 1): low [coefficient of variation $(\mathrm{CV})<10 \%$ ], moderate $(10 \%<\mathrm{CV}<100 \%)$, and high (CV > 100\%) (Zheng et al., 2004). According to the method of Xiong et al. (2011) (Table 1), the 80 experimental plots were categorized into two types: potential-mild rocky desertification and moderate-severe rocky desertification.

$$
C V=\frac{S D}{M N} \times 100 \%
$$

$\mathrm{SD}$ is the standard deviation; $\mathrm{MN}$ is the mean.

Table 1. Classification standard of karst rock desertification

\begin{tabular}{c|c|c|c}
\hline $\begin{array}{c}\text { Rocky } \\
\text { desertification } \\
\text { level }\end{array}$ & $\begin{array}{c}\text { Rock } \\
\text { exposure } \\
\text { rate }\end{array}$ & $\begin{array}{c}\text { Vegetation }+ \\
\text { soil coverage }\end{array}$ & Reference indicator \\
\hline $\begin{array}{c}\text { No rock } \\
\text { desertification }\end{array}$ & $<20$ & $>80$ & $\begin{array}{c}\text { Nonterraced dry hillside land with a slope of } \leq 15^{\circ}, \text { dikes, } \\
\text { construction land, etc., with good ecological environment, } \\
\text { densely populated trees and shrubs, with no or } \\
\text { insignificant soil erosion; suitable for agricultural, forestry, } \\
\text { or animal husbandry production }\end{array}$ \\
\hline $\begin{array}{c}\text { Potential rocky } \\
\text { desertification }\end{array}$ & $20-30$ & $80-70$ & $\begin{array}{c}\text { Nonterraced dry hillside land and grassland, etc. with a } \\
\text { slope of }>15^{\circ}, \text { with sparsely populated arbor, shrubby and } \\
\text { herbaceous vegetation, and good soil-forming conditions } \\
\text { but obvious soil erosion; showing a tendency of rock } \\
\text { exposure }\end{array}$ \\
\hline $\begin{array}{c}\text { Mild rocky } \\
\text { desertification }\end{array}$ & $31-50$ & $69-50$ & $\begin{array}{c}\text { Rocks begin to be exposed, with obvious soil erosion, low } \\
\text { vegetative patch structure, and dominance of sparse shrubs } \\
\text { or artificial dry-land vegetation }\end{array}$ \\
\hline $\begin{array}{c}\text { Moderate rock } \\
\text { desertification }\end{array}$ & $51-70$ & $49-30$ & $\begin{array}{c}\text { Rocky desertification is intensifying, with severe soil } \\
\text { erosion, shallow topsoil, dominance of rocky hillside land, } \\
\text { and sparse shrub-grass zone }\end{array}$ \\
\hline $\begin{array}{c}\text { Severe rock } \\
\text { desertification }\end{array}$ & $>70$ & $<30$ & $\begin{array}{c}\text { Rocky desertification is severe, with essentially no soil } \\
\text { erosion due to the absence of topsoil, and dominant with } \\
\text { lands difficult to use that is about to lose agricultural value }\end{array}$ \\
\hline
\end{tabular}


The relationship between plant leaf and litter stoichiometry and soil environmental factors was analyzed using Canoco 4.5 for Windows. First, we performed detrended correspondence analysis on the indicators and found that when the maximum value of the gradient length was less than 3, the linear ranking method was suitable, so we adopted the redundancy analysis of the linear model as the ranking model to examine the relationship between the stoichiometry and the environmental factors. The importance of soil environmental factors was ranked through the Monte Carlo test, and the effect of individual environmental factors on plant stoichiometry was determined using the $t$-value biplot of Canoco 4.5. When interpreting the biplot, if the arrowed connection line of a certain plant stoichiometric indicator was completely within a circle, then it indicated that this indicator was significantly correlated with the soil environmental factor (in the red circle: significant positive correlation; in the blue circle: significant negative correlation; the percentage and length of the arrow that fall within the circle represent the strength of the correlation) (Leps and Smilauer, 2003).

\section{Results and analysis}

\section{Stoichiometric characteristics of nutrients of Karst rocky desertification ecosystems}

The contents of $\mathrm{C}, \mathrm{N}$, and $\mathrm{P}$ in plant leaves in karst rocky desertification ecosystems were higher than those in litter or soil, while the ratios of $\mathrm{C}: \mathrm{N}, \mathrm{C}: \mathrm{P}$, and $\mathrm{N}: \mathrm{P}$ of litter were higher than those of plant leaves or soil. The CVs of stoichiometric values of different nutrients differed, and the variations were mostly moderate. Overall, the CV of stoichiometric values of soil was the highest, followed by that of litter and that of plant leaves. The $\mathrm{CV}$ of stoichiometric values of soil was significantly different from those of soil or litter $(P<0.05)$ (Table 2$)$.

Table 2. Stoichiometric characteristics of nutrients in karst areas of rocky desertification

\begin{tabular}{c|c|c|c|c|c|c|c|c|c|c|c|c}
\hline & \multicolumn{2}{|c|}{$\mathbf{C}$} & \multicolumn{2}{c|}{$\mathbf{N}$} & \multicolumn{2}{c|}{$\mathbf{P}$} & \multicolumn{2}{c|}{ C:P } & \multicolumn{2}{c}{ N:P } \\
\cline { 2 - 12 } & Mean \pm SE & $\begin{array}{c}\text { CV } \\
(\%)\end{array}$ & Mean \pm SE & $\begin{array}{c}\text { CV } \\
(\%)\end{array}$ & Mean \pm SE & $\begin{array}{c}\text { CV } \\
(\%)\end{array}$ & Mean \pm SE & $\begin{array}{c}\text { CV } \\
(\%)\end{array}$ & Mean \pm SE & $\begin{array}{c}\text { CV } \\
(\%)\end{array}$ & Mean \pm SE & $\begin{array}{c}\text { CV } \\
(\%)\end{array}$ \\
\hline $\begin{array}{c}\text { Plant } \\
\text { leaves }\end{array}$ & $482.96+4.36 \mathrm{a}$ & 8 & $12.39+0.6 \mathrm{a}$ & 40 & $1.76+0.07 \mathrm{a}$ & 35 & $43.77 \pm 1.57 \mathrm{a}$ & 30 & $303.09 \pm 11.41 \mathrm{a}$ & 32 & $7.06 \pm 0.16 \mathrm{a}$ & 19 \\
\hline Litter & $166.4+4.8 \mathrm{a}$ & 22 & $10.55+0.31 \mathrm{a}$ & 23 & $1.24+0.07 \mathrm{~b}$ & 44 & $46.95 \pm 1.68 \mathrm{a}$ & 28 & $432.41 \pm 18.50 \mathrm{~b}$ & 34 & $9.61 \pm 0.46 \mathrm{~b}$ & 38 \\
\hline Soil & $38.24+1.73 \mathrm{~b}$ & 40 & $2.62+0.15 \mathrm{~b}$ & 50 & $0.9+0.05 \mathrm{c}$ & 43 & $18.84 \pm 1.40 \mathrm{~b}$ & 65 & $51.81 \pm 3.66 \mathrm{c}$ & 65 & $3.02 \pm 0.14 \mathrm{c}$ & 40 \\
\hline
\end{tabular}

In the same column, the different lower-case letters represent statistically significant differences $(P<0.05)$; the data are presented as mean $\pm \mathrm{SE}$ (standard error)

\section{The stoichiometric characteristics of plant leaf, litter, and soil under different levels of rocky desertification}

The stoichiometric characteristics differed significantly between the areas with different levels of rocky desertification (Fig. 4). The C:N:P ratios of plant leaves, litter, and soil in the area of potential-mild rocky desertification were 361:7:1, 498:12:1, and 69:3:1, respectively, and those in the area of moderate-severe rocky desertification were 224:7:1, 301:6:1, and 29:3:1, respectively. Compared with the area with a higher level of rocky desertification, the area with a lower level of rocky desertification had higher ratios of $\mathrm{C}: \mathrm{N}$ and $\mathrm{C}: \mathrm{P}$ in the soil and plant leaves and higher ratios of $\mathrm{C}: \mathrm{P}$ and $\mathrm{N}: \mathrm{P}$ in the 
litter. The N:P ratio of plant leaves and litter were 7.25 and 12.58 in the area of potential-mild rocky desertification, respectively, and 6.91 and 6.64 in the area of moderate-severe rocky desertification. The results indicate that the $\mathrm{C}$ content and the $\mathrm{N}: \mathrm{P}$ ratios of plant leaves and litter in the area of potential-mild rocky desertification are higher than in the area of moderate-severe rocky desertification.
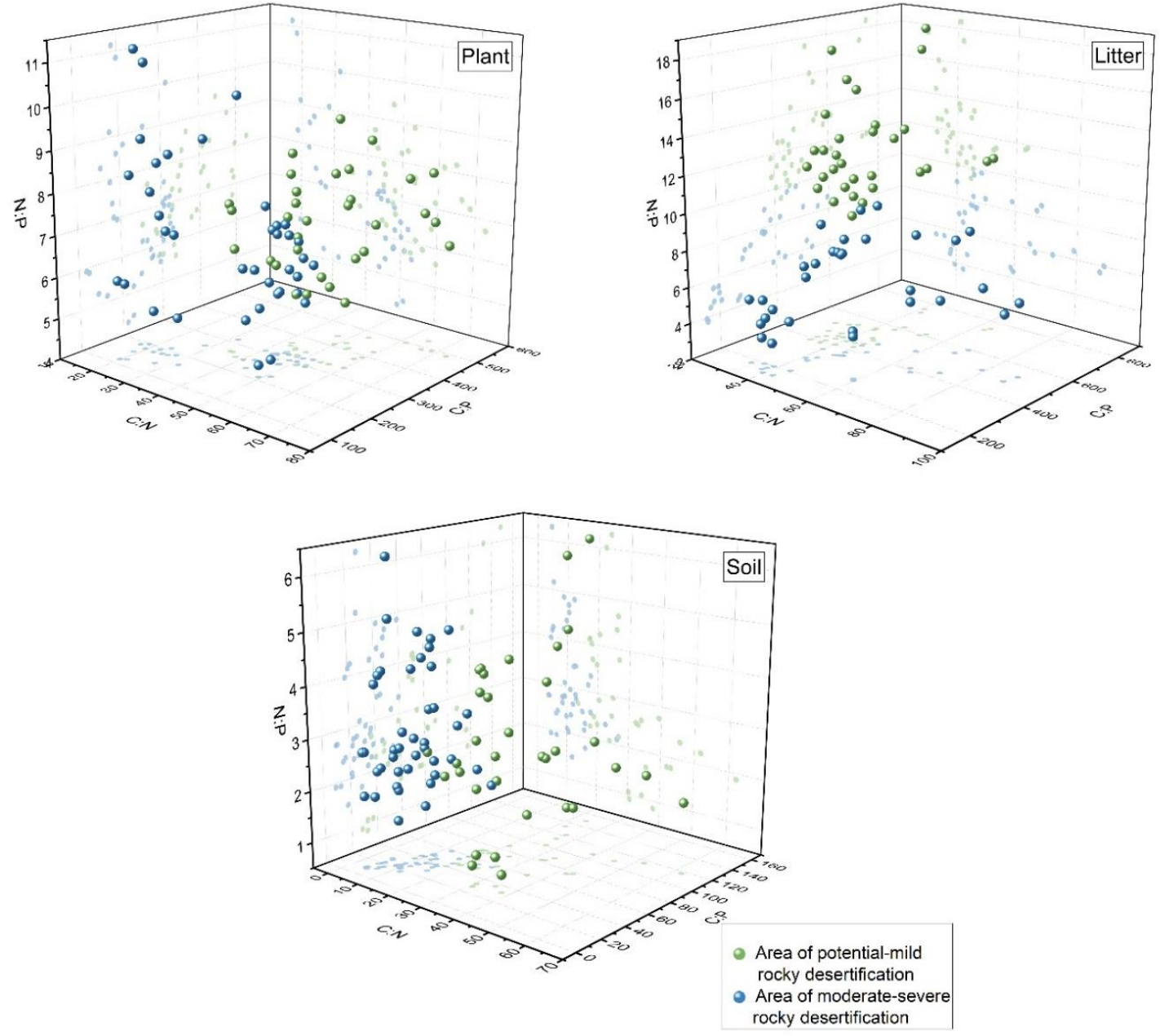

Figure 4. Stoichiometric characteristics of areas with different levels of rocky desertification

\section{Relationship between stoichiometric characteristics of plant leaves, litter, and soil environmental factors in areas of rocky desertification}

Stoichiometric characteristics of the areas of rocky desertification and RDA ordination of their respective interpretation powers

The stoichiometric characteristics and the RDA ordination of their respective interpretation powers (Table 3) showed that the cumulative interpretation power of the area of potential-mild rocky desertification and that of the area of moderate-severe rocky desertification on the first and second RDA ordination axes were $72.6 \%$ and $68.4 \%$, respectively. The correlation between the stoichiometry of the first and second axes and the soil environmental factors of the area of potential-mild rocky desertification were 0.953 and 0.969 , respectively, and the correlation between the 
stoichiometry of the first and second axes and the soil environmental factors of the area of moderate-severe rocky desertification were 0.916 and 0.853 , respectively. Therefore, the two ordination axes were essentially vertical, indicating that the ordination results were credible. The cumulative interpretation power on the relationship between the stoichiometry and the soil environmental factors was $80 \%$ and $90.9 \%$ for the area of potential-mild rocky desertification and the area of moderate-severe rocky desertification, respectively, accounting for $81.5 \%$ and $91.8 \%$ of the total interpretation power. These data indicate that the first and second axes can well reflect the relationship between the stoichiometry and soil environmental factors.

Table 3. The stoichiometric characteristics and their RDA ordination analysis on the interpretation power

\begin{tabular}{|c|c|c|c|c|c|}
\hline & Ordination axis & Axis I & Axis II & Axis III & Axis IV \\
\hline \multirow{6}{*}{$\begin{array}{l}\text { Potential-mild } \\
\quad \text { rock } \\
\text { desertification }\end{array}$} & $\begin{array}{c}\text { Interpretation power of stoichiometric } \\
\text { characteristics, } \% \\
\end{array}$ & 43.4 & 29.2 & 9.5 & 6 \\
\hline & $\begin{array}{c}\text { Correlation between stoichiometric } \\
\text { characteristics and the soil environmental } \\
\text { factors }\end{array}$ & 0.953 & 0.969 & 0.872 & 0.95 \\
\hline & $\begin{array}{c}\text { Cumulative interpretation power of } \\
\text { stoichiometric characteristics, } \%\end{array}$ & 43.4 & 72.6 & 82.1 & 88.1 \\
\hline & $\begin{array}{l}\text { The cumulative interpretation power of } \\
\text { stoichiometry-soil environmental factor } \\
\text { relationship, } \%\end{array}$ & 48.3 & 80.0 & 91.4 & 98.1 \\
\hline & Canonical eigenvalue & & 89.9 & & \\
\hline & Total eigenvalue & & 1.00 & & \\
\hline \multirow{6}{*}{$\begin{array}{l}\text { Moderate- } \\
\text { mild rocky } \\
\text { desertification }\end{array}$} & $\begin{array}{l}\text { Interpretation power of stoichiometric } \\
\text { characteristics } 1 \%\end{array}$ & 53.3 & 15.1 & 4.4 & 1.7 \\
\hline & $\begin{array}{c}\text { Correlation between stoichiometry and } \\
\text { soil environmental factors }\end{array}$ & 0.916 & 0.853 & 0.643 & 0.781 \\
\hline & $\begin{array}{c}\text { Cumulative interpretation power of } \\
\text { stoichiometric characteristics } 1 \%\end{array}$ & 53.3 & 68.4 & 72.7 & 74.5 \\
\hline & $\begin{array}{l}\text { The cumulative interpretation power of } \\
\text { stoichiometry-soil environmental factor } \\
\text { relationship /\% }\end{array}$ & 70.8 & 90.9 & 96.7 & 99.0 \\
\hline & Canonical eigenvalue & & 0.752 & & \\
\hline & Total eigenvalue & & 1.00 & & \\
\hline
\end{tabular}

The 2-D RDA ordination results show that the lengths of arrowed connection lines of the soil environmental factors $\mathrm{pH}, \mathrm{TP}, \mathrm{C}: \mathrm{P}$, and SOC were the longest in Figure $5 a$ and that those of $\mathrm{C}: \mathrm{P}, \mathrm{TP}, \mathrm{C}: \mathrm{N}$, and $\mathrm{SWC}$ were the longest in Figure 5b, indicating that these soil environmental factors had good interpretation power for the differences in the changes in plant leaves and litter, which are consistent with the importance ordination results shown in Table 4. Figure $5 a$ also shows that the directions of the arrows between C:P and DC:P, between $\mathrm{pH}$ or SOC and DC, and between TP or SWC and DP were consistent; that the angles between the lines were small; and that the factors had a positive correlation, indicating that $\mathrm{C}: \mathrm{P}, \mathrm{pH}, \mathrm{SOC}, \mathrm{TP}$, and $\mathrm{SWC}$ had a positive effect on some plant ecological stoichiometric characteristics and were important factors affecting plant ecological stoichiometric properties in the area of 
potential-mild rocky desertification. Figure $5 b$ shows that the directions of the arrows between $\mathrm{C}: \mathrm{P}$ and ZC:P, between TP and ZP, between $\mathrm{C}: \mathrm{P}$ and $\mathrm{ZC}: \mathrm{P}$, between SOC or $\mathrm{N}: \mathrm{P}$ and DN:P, and between SWC and ZN were consistent; that the angles between the lines were small; and that the factors had a positive correlation. The results indicate that $\mathrm{C}: \mathrm{P}, \mathrm{TP}, \mathrm{C}: \mathrm{N}, \mathrm{SWC}, \mathrm{C}: \mathrm{P}$, and $\mathrm{N}: \mathrm{P}$ had a positive effect on some plant ecological stoichiometric characteristics and were important factors affecting plant ecological stoichiometric properties in the area of moderate-severe rocky desertification.
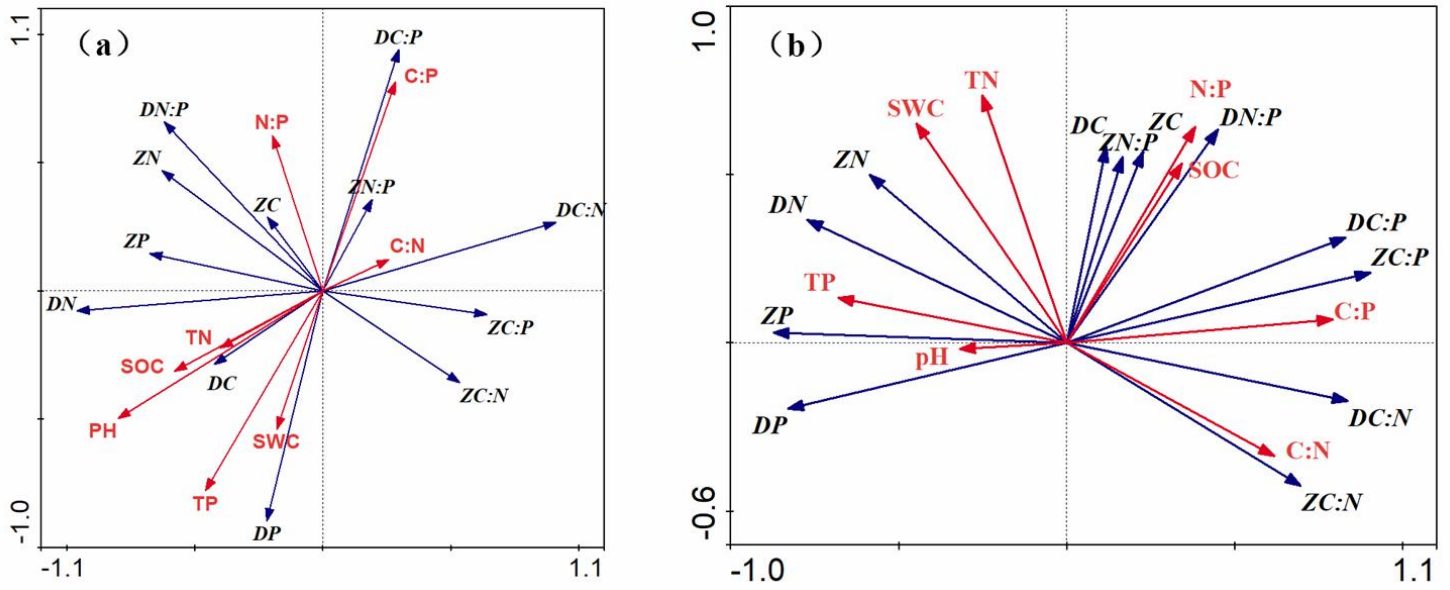

Figure 5. Redundancy analysis on plant stoichiometric characteristics and soil environmental factors. Note: $p H, S O C, T N, T P, C: N, C: P$, and $N: P$ are the soil $p H$, soil organic carbon content, soil total nitrogen content, soil total phosphorus content, and their respective stoichiometric ratios, respectively; $Z C, Z N, Z P, Z C: N, Z C: P$, and $Z N: P$ are the organic carbon content, total nitrogen content, and total phosphorus content in plant leaves and their respective stoichiometric ratios, respectively; $D C, D N, D P, D C: N, D C: P$, and $D N: P$ are the organic carbon content in the litter, total nitrogen content in plant litter, total phosphorus content in plant litter, and their respective stoichiometric ratios, respectively. Part (a) shows the RDA results of plant stoichiometric characteristics and soil environmental factors in the area of potential-mild rocky desertification. Part (b) shows the RDA results of plant stoichiometric characteristics and soil environmental factors in the area of moderate-severe rocky desertification

Ranking the importance of soil environmental factors to plant stoichiometric characteristics

We performed the Monte Carlo test to rank the eight soil environmental factors (Table 4) and found that the effects of soil environmental factors on plant stoichiometric characteristics differed between areas with different levels of rocky desertification. The order of importance of the soil environmental factors in the area of potential-mild rocky desertification was $\mathrm{pH}>\mathrm{TP}>\mathrm{C}: \mathrm{P}>\mathrm{SOC}>\mathrm{N}: \mathrm{P}>\mathrm{TN}>\mathrm{SWC}>\mathrm{C}: \mathrm{N}$. The effects of $\mathrm{pH}, \mathrm{TP}, \mathrm{C}: \mathrm{P}$, and SOC on plant stoichiometric characteristics were significant $(P<0.05)$. Compared with other soil environmental factors, $\mathrm{pH}$ could better represent the difference in plant stoichiometric characteristics. The order of importance of the soil environmental factors in the area of moderate-severe rocky desertification was $\mathrm{C}: \mathrm{P}>\mathrm{TP}>\mathrm{C}: \mathrm{N}>\mathrm{SWC}>\mathrm{N}: \mathrm{P}>\mathrm{TN}>\mathrm{SOC}>\mathrm{pH}$. The effects of C:P, TP, C:N, and 
SWC were significant $(P<0.05)$, and compared with the other soil environmental factors, $\mathrm{C}: \mathrm{P}$ better represented the difference in plant stoichiometric characteristics.

Table 4. Monte Carlo test ranking of eight soil environmental factors

\begin{tabular}{c|c|c|c|c|c}
\hline & Soil factor & $\begin{array}{c}\text { Order of } \\
\text { importance }\end{array}$ & $\begin{array}{c}\text { Interpretation } \\
\text { power (\%) }\end{array}$ & $\begin{array}{c}\text { Importance } \\
(\mathbf{F})\end{array}$ & $\begin{array}{c}\text { Significance } \\
(\mathbf{P})\end{array}$ \\
\hline & $\mathrm{pH}$ & 1 & 35.6 & 6.625 & 0.002 \\
& $\mathrm{TP}$ & 2 & 27.8 & 4.625 & 0.006 \\
Area of & $\mathrm{C}: \mathrm{P}$ & 3 & 23.4 & 3.666 & 0.012 \\
potential-mild & $\mathrm{SOC}$ & 4 & 19 & 2.809 & 0.036 \\
rocky & $\mathrm{N}: \mathrm{P}$ & 5 & 13.5 & 1.874 & 0.128 \\
desertification & $\mathrm{TN}$ & 6 & 10.9 & 1.472 & 0.218 \\
& $\mathrm{SWC}$ & 7 & 10.0 & 1.336 & 0.264 \\
& $\mathrm{C:N}$ & 8 & 4.5 & 0.57 & 0.684 \\
\hline & $\mathrm{C}: \mathrm{P}$ & 1 & 33.7 & 9.138 & 0.002 \\
& $\mathrm{TP}$ & 2 & 25.9 & 6.294 & 0.004 \\
Area of & $\mathrm{C:N}$ & 3 & 22.6 & 5.252 & 0.004 \\
moderate- & $\mathrm{SWC}$ & 4 & 17.3 & 3.76 & 0.016 \\
severe rocky & $\mathrm{N}: \mathrm{P}$ & 5 & 14.7 & 3.106 & 0.066 \\
desertification & $\mathrm{TN}$ & 6 & 12.3 & 2.525 & 0.076 \\
& $\mathrm{SOC}$ & 7 & 10.8 & 2.184 & 0.134 \\
& $\mathrm{pH}$ & 8 & 5.6 & 1.067 & 0.354 \\
\hline
\end{tabular}

\section{Effects of individual soil environmental factors on plant stoichiometry}

We generated impact diagrams of individual soil environmental factors using the tvalue biplots of the first four factors affecting plant stoichiometry in the area of potential-mild rocky desertification (Fig. 6). The Canoco biplot for $\mathrm{pH}$ (Fig. 6a) shows that the DP arrow falls within the red circle and that the DC:P arrow falls within the blue circle, indicating that $\mathrm{pH}$ had a significantly positive correlation with DP but a significantly negative correlation with DC:P. Figure $6 b$ shows that soil TP had a significantly positive correlation with $\mathrm{DN}: \mathrm{P}$ and $\mathrm{DN}$ and a positive correlation with plant $\mathrm{C}, \mathrm{N}$, and P. Figure $6 c$ and $d$ show that the plant stoichiometric indicators do not fall within the circle but mostly pass through the red circle or the blue circle, indicating that the plant stoichiometric characteristics were correlated $(P<0.05)$ with the soil environmental factors $\mathrm{C}: \mathrm{P}$ and SOC, but not highly correlated $(P<0.01)$.

The t-value biplot of the area of moderate-severe rocky desertification is shown in Figure 7. Figure $7 a$ shows that the DC:N and ZC:N arrows pass through the red circle and that the ZC:N arrow has more of its length within the red circle, indicating that $\mathrm{C}: \mathrm{P}$ had a positive correlation with DC:N and ZC:N (with a stronger correlation for ZC:N). Figure $7 b$ and $c$ show that DC, ZC, ZN:P, DN:P, DC:P, and ZC:P pass through the blue circle and the red circle, respectively, indicating that these environmental factors were correlated negatively with TP but positively with C:N. Figure $7 d$ shows the analysis result of SWC, indicating that SWC had a significantly positive correlation with ZP and $\mathrm{DP}$, which fall into the red circle, but a significantly negative correlation with DN:P, DC:P, ZC:P, and DC:N, which fall into the blue circle. 

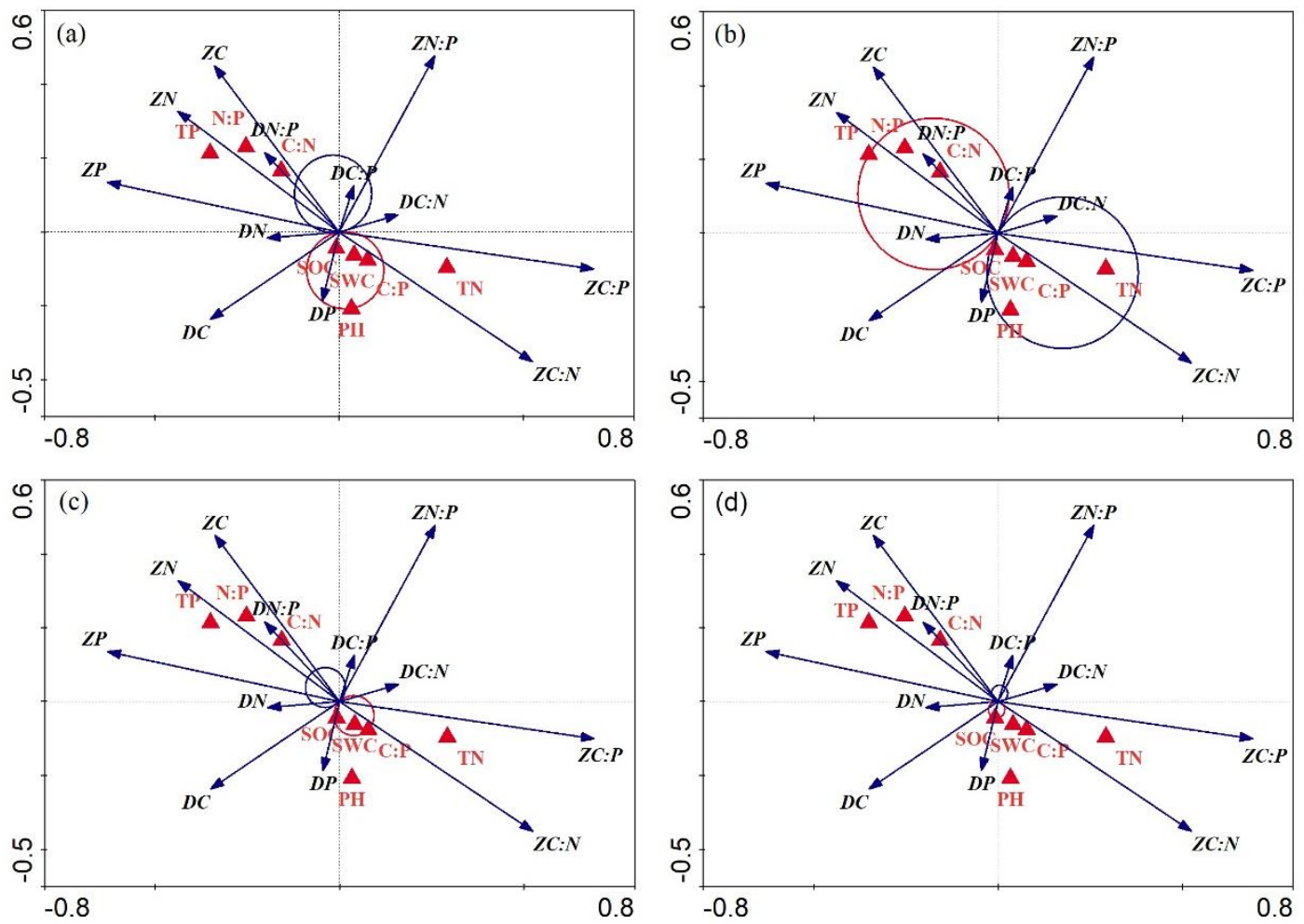

Figure 6. Effect of individual soil environmental factors on plant stoichiometry in the area of potential-mild rocky desertification. (a) $\mathrm{pH} ;$ (b) TP; (c) C:P; (d) SOC

\section{Discussion}

\section{Ecological stoichiometric characteristics of karst areas of rocky desertification}

In this study, we examined the stoichiometric characteristics of plant leaves, litter, and soil of karst areas and found that the $\mathrm{C}, \mathrm{N}$, and $\mathrm{P}$ contents of plant leaves in karst areas of rocky desertification were higher than those of litter or soil. This was because the $\mathrm{C}, \mathrm{N}$, and $\mathrm{P}$ contents of plant leaves, an important nutrient storage organ, are much higher than in other plant organs (Minden and Kleyer, 2014). After fresh leaves fall, the organic components such as crude fat, tannins, and soluble sugars are decomposed, leading to significantly reduced $C$ content in the litter (Yang et al., 2007). Litter had lower contents of $\mathrm{N}$ and $\mathrm{P}$ than leaves. This is because before leaves fall, the nutrients in the leaves are transferred to other components, absorbed, and utilized. The reduction in $\mathrm{N}$ may happen because the leaves utilizes nitrogen in photosynthesis, and high $\mathrm{N}$ use efficiency reduces the $\mathrm{P}$ content in litter (Zhao et al., 2016). Plants absorb $\mathrm{N}$ and $\mathrm{P}$ from the soil and further transfer some nutrients to plants through the nutrient reabsorption process, resulting in larger changes to the $\mathrm{N}$ and $\mathrm{P}$ contents in litter than in plant leaves, and thus the $\mathrm{C}: \mathrm{N}$ and $\mathrm{C}: \mathrm{P}$ contents are found in the order litter $>$ plant $>$ soil (Zeng et al., 2015). Soil nutrient content is an important indicator for evaluating organic matter composition and soil quality, and the soil nutrient variability in the same ecosystem is largely affected by environmental factors (Li et al., 2018). Soil nutrients in karst areas showed moderate variation but had significant fluctuations, which are caused by the changes in environmental factors derived from complicated landforms, high spatial heterogeneity, and the interference of human activities, which are consistent with the conclusions of Zhu et al. (2013) and Li et al. (2014). 

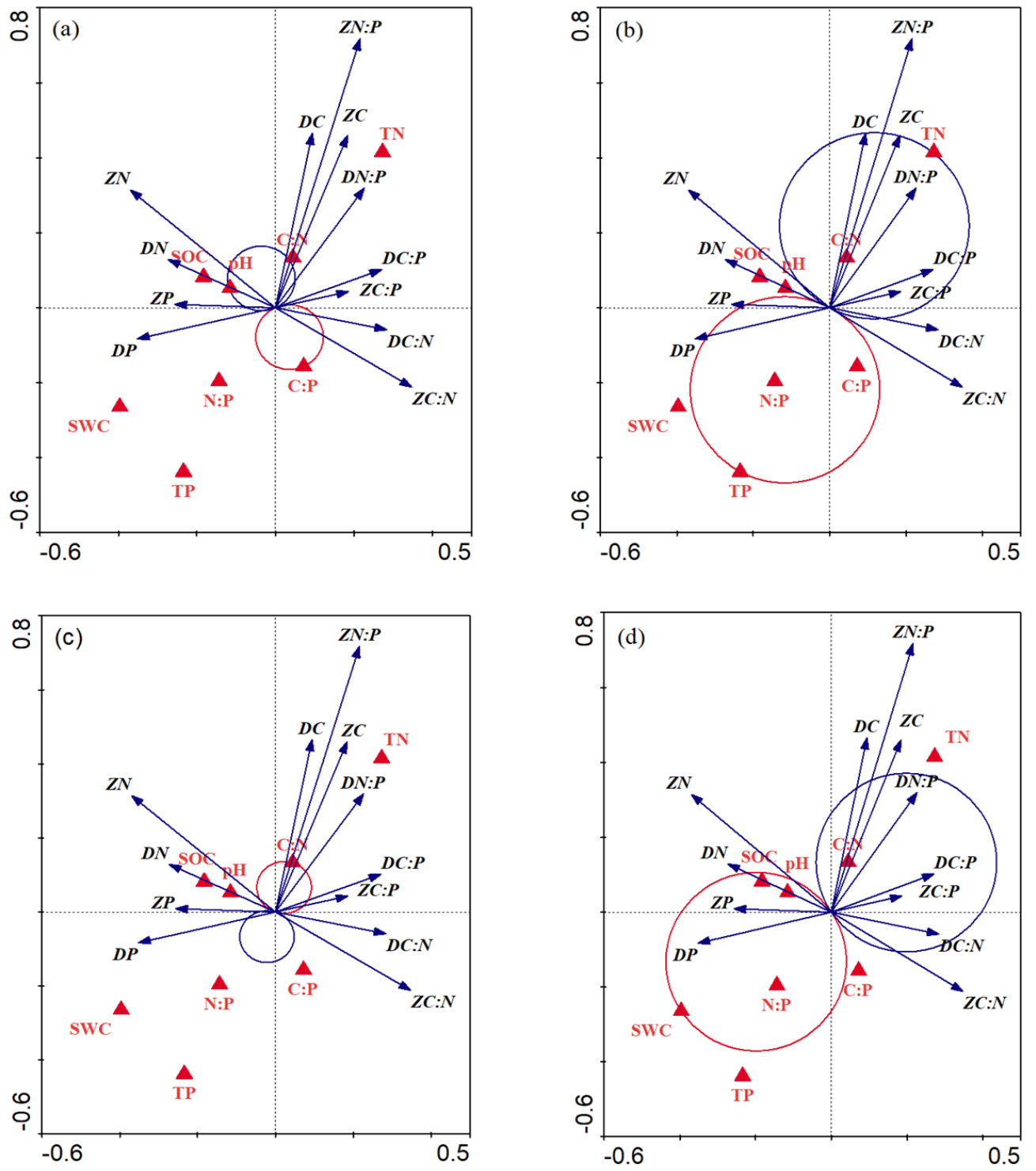

Figure 7. Effect of individual soil environmental factors on plant stoichiometry in the area of moderate-severe rocky desertification. (a) C:P; (b) TP; (c) C:N; (d) SWC

In this study, the soil $\mathrm{P}$ content of the areas of rocky desertification was $0.9 \mathrm{mg} \cdot \mathrm{g}^{-1}$, which is lower than that of other ecosystems (Koerselma and Meuleman, 1996; Jiao et al., 2013). This was likely caused by the strong leaching effect derived from high precipitation in karst areas in southwestern China. However, compared with the average content of soil P in China $(0.56 \mathrm{~g} / \mathrm{kg}$ ) (Tian et al., 2010), the P content of the karst areas is still higher, indicating that despite strong leaching effects in the rocky desertification environment, the $\mathrm{P}$ content of the karstification product from bare rocks can readily accumulate in the soil, showing a significant aggregation effect, which is consistent with the findings of Sheng et al. (2013). We also found that the average $\mathrm{C}$ content in plant leaves was $482.96 \mathrm{mg} \cdot \mathrm{g}^{-1}$, which is higher than that $(464.00$ $\mathrm{mg} \cdot \mathrm{g}^{-1}$ ) of 492 terrestrial plant species around the world reported by Elser et al. (2000) and that $\left(438.00 \mathrm{mg} \cdot \mathrm{g}^{-1}\right)$ of China's grassland ecosystem (He et al., 2006), indicating 
that the karst area has strong $\mathrm{C}$ storage capacity and thus high accumulation of organic matter. The average $\mathrm{N}$ content in plant leaves was $12.39 \mathrm{mg} \cdot \mathrm{g}^{-1}$, which is significantly lower than that $\left(20.09 \mathrm{mg} \cdot \mathrm{g}^{-1}\right)$ at the global scale (Reich and Oleksyn, 2004) and that of 753 species reported by Han et al. (2005), indicating $\mathrm{N}$ deficiency in the karst area, likely because the high precipitation in the region (over $980 \mathrm{~mm}$ annually) is prone to cause the leaching of available nitrogen, which has a high mobility.

\section{Ecological stoichiometric characteristics of areas with different levels of rocky desertification}

Due to differences in geographical conditions, the $\mathrm{N}$ and $\mathrm{P}$ contents and the stoichiometric characteristics of $\mathrm{C}: \mathrm{N}: \mathrm{P}$ of plant leaves in different habitats and different tree species vary profoundly (Reich and Oleksyn, 2004; Han et al., 2005). In this study, we found that the $\mathrm{C}$ content in plant leaves in the area of potential-mild rocky desertification was higher than that in the area of moderate-severe rocky desertification. Because the soil is a primary environmental factor in karst areas, its stoichiometric characteristics affect the plant community characteristics of areas with different levels of rocky desertification (Zhao et al., 2019). In the area of moderatesevere rocky desertification, the rock exposure rate was high, the vegetation coverage was low, and the biomass was low, leading to the reduced stock of soil organic carbon and the accelerated decomposition of organic matter and thus a lower $\mathrm{C}$ content than in the area with a lower level of rocky desertification. This finding is consistent with the findings of Yang (2000) and Long et al. (2002). They found that soil C:N is inversely proportional to the decomposition rate of organic matter and that the soil with a lower C:N ratio is faster at mineralization (Zhu et al., 2013). In this study, we found that the soil $\mathrm{C}: \mathrm{N}$ ratio was 28.72 in the area of potential-mild rocky desertification and was 10.85 in the area of moderate-severe rocky desertification. The soil $\mathrm{C}: \mathrm{N}$ ratio in the area of moderate-severe rocky desertification was lower than the global average (14.3) (Zhao et al. 2015), indicating higher rates of decomposition and mineralization of soil organic matter. The $\mathrm{C}: \mathrm{N}$ and $\mathrm{C}: \mathrm{P}$ ratios in plant leaves and soil in the area of potential-mild rocky desertification were higher than those in the area of moderate-severe rocky desertification because in the area of moderate-severe rocky desertification, topsoil was shallow and had high temperature and humidity, weak nutrient retention ability, and fast nutrient turnover, leading to low nutrient use efficiency and nutrient resorption rate in plants (Cui et al., 2015). The critical values for plant $\mathrm{N}: \mathrm{P}$ are 14 and 16 . When $\mathrm{N}: \mathrm{P}<14$, the ecosystem is N-limited, and when $\mathrm{N}: \mathrm{P}>16$, it is P-limited (Koerselman and Meuleman, 1996; Tessier and Raynal, 2003). In this study, we found that the N:P ratios of the area of potential-mild rocky desertification and the area of moderate-severe rocky desertification were 6.91 and 7.25 , respectively, indicating that both areas were $\mathrm{N}$-limited. In the shrub and grass vegetation of the karst areas, we found that $\mathrm{N}$ was deficient while $\mathrm{P}$ was sufficient, mainly because in these areas, the rock exposure rate was high, the vegetation coverage was low, nutrients were concentrated in the arborous layer, and the symbiotic nitrogen fixation system and the slightly weathered soil were scarce (Hedin, 2004). Thus, supplementation with $\mathrm{N}$ fertilizer during the control process can increase the $\mathrm{N}$ content of the vegetation. Our results indicate that the limiting factors inhibit vegetation recovery and development and that limiting factors should be effectively regulated in forest management strategies. 


\section{Driving mechanisms of the effect of soil environmental factors on plant stoichiometry}

The chemical elements of vegetation are mainly derived from the soil, and their contents are closely related to their soil contents. $\mathrm{C}, \mathrm{N}$, and $\mathrm{P}$ are the basic constituent elements of plants that are converted in the plant-litter-soil continuum, manifesting the nutrient cycling and use efficiency (Zeng et al., 2015). Soil pH, TP, C:P, SOC, C:N, and SWC are the main driving factors affecting plant stoichiometry. The soil environmental factors TP and C:P significantly affected the stoichiometric characteristics of the vegetation in both areas of rocky desertification, indicating that the $\mathrm{P}$ level in plants is closely coupled with that in soil. Soil $\mathrm{P}$ level is positively correlated to $\mathrm{C}, \mathrm{N}$, and $\mathrm{P}$ levels in plant leaves, indicating that the soil $\mathrm{P}$ can facilitate the absorption of $\mathrm{C}, \mathrm{N}$, and $\mathrm{P}$ by plant leaves. The reason that $\mathrm{P}$ is an important factor is that the $\mathrm{P}$ in soil is directly produced by rock weathering and thus is a sedimentary element. In karst areas, soil and rock are in direct contact, which is prone to cause soil erosion and slides. Therefore, the fluctuation in the content of $\mathrm{P}$ exerts a greater influence on the ratios of elements than other fluctuations. In the future plant nutrient recycling and utilization processes, soil $\mathrm{P}$ should be optimized and adjusted to achieve nutrient balance.

The soil environmental factor TP was positively correlated with $\mathrm{DN}: \mathrm{P}$ and $\mathrm{DN}$ (Fig. 6b) but negatively correlated with DC, ZC, ZN:P, DN:P, DC:P, and ZC:P (Fig. 7b), indicating that in environments with different levels of rocky desertification, the driving effect of soil environmental factors on plant nutrient absorption varies, which is consistent with the findings of Chen et al. (2018). The soil environmental factors TP (Fig. 7b) and SWC (Fig. $7 d$ ) in the moderate-severe rocky desertification demonstration area showed similar correlations in the analysis of the effects of individual environmental factors, indicating that the driving mechanisms of the two are identical. This is mainly because the high rainfall in the karst area accelerates TP leaching, which, coupled with ground runoff, leads to the simultaneous losses of soil TP and SWC and thus a certain correlation between TP and SWC. SWC showed a significantly positive correlation with ZP and DP and a significantly negative correlation with DN:P, DC:P, ZC:P, and DC:N (Fig. 7d), indicating that the increase in SWC significantly increases $\mathrm{P}$ contents in plant leaves and litter while decreasing the contents of $\mathrm{C}: \mathrm{N}, \mathrm{C}: \mathrm{P}$, and $\mathrm{N}: \mathrm{P}$ of litter, indicating that SWC can effectively increase the nutrient transfer rate of plant leaves, resulting in reduced $\mathrm{C}: \mathrm{N}$, $\mathrm{C}: \mathrm{P}$, and $\mathrm{N}: \mathrm{P}$ ratios in litter.

The changes to soil nutrient supply in the environment of karst rocky desertification can affect various plant physiological and biochemical reactions to some extent. After long evolutionary adaptation, plants form relatively stable elemental stoichiometries, which also reflects plants' adaptation strategy to extreme environments. The RDA on the area of potential-mild rocky desertification showed that soil $\mathrm{pH}$ played the most critical role in plant stoichiometry. Past studies have shown that soil $\mathrm{pH}$ directly affects the decomposition, mineralization, redox reaction, and enzyme reaction rates of soil organic matter, and species richness is positively correlated with $\mathrm{pH}$ value (Dick et al., 2000; Xu et al., 2006; Tian et al., 2019). The species richness and the $\mathrm{pH}$-driving impact of the area of potential-mild rocky desertification was higher than those of the area of moderate-severe rocky desertification. Among the soil environmental factors in area of moderate-severe rocky desertification, soil C:P showed a more profound effect and a positive correlation with DC:N and ZC:N (Fig. 7a), indicating that the increase in soil $\mathrm{C}: \mathrm{P}$ can promote the $\mathrm{C}: \mathrm{N}$ in plant leaves, while the $\mathrm{C}: \mathrm{N}$ in litter is fully in line with the characteristics of $\mathrm{C}: \mathrm{N}$ in plant leaves, consistent with the conclusions on the stoichiometric characteristics of wetland plants and litter by Wang et al. (2011). 


\section{Conclusions}

Nutrient cycling and transfer occur in the plant-litter-soil continuum in karst areas of rocky desertification, which is manifested in the $\mathrm{C}, \mathrm{N}$, and $\mathrm{P}$ contents in plant leaves being higher than those in litter or soil.

The leaves of plants in karst areas showed $\mathrm{N}$ deficiency, $\mathrm{P}$ sufficiency, and a strong $\mathrm{C}$ storage capacity. Supplementation with $\mathrm{N}$ fertilizer during the control process can increase the vegetation biomass yield.

The decomposition and mineralization rates of soil organic matter in the area of moderate-severe rocky desertification is higher than in the area of potential-mild rocky desertification. The order of importance of soil environmental factors in the area of potential-mild rocky desertification is $\mathrm{pH}>\mathrm{TP}>\mathrm{C}: \mathrm{P}>\mathrm{SOC}$. The soil $\mathrm{pH}$ has the strongest driving effect on plant stoichiometry. The order of importance of soil environmental factors in the area of moderate-severe rocky desertification is $\mathrm{C}: \mathrm{P}>\mathrm{TP}>\mathrm{C}: \mathrm{N}>\mathrm{SWC}$. The soil $\mathrm{C}: \mathrm{P}$ has the strongest driving effect on plant stoichiometry.

It is necessary to target the primary factors for fertilization management and nutrient transport protection in future rock desertification control. In the diagnosis of plant nutrient restriction, in addition to considering the role of soil environmental nutrient factors, it is also necessary to increase the mechanism of plant photosynthesis and respiration on the maintenance of plant nutrients, as well as the decomposition and interference of underforest microenvironment, soil animals and microbial activities on litter. In the future, we should increase the systematic research of multi-disciplinary, multi-angle and multi-thinking. At the same time, the environment and livelihood problems caused by stony desertification need to be paid more attention all over the world.

Acknowledgements. This research was funded by the Project of National Key Research and Development Program of China in the 13th Five-year Plan Period: Ecological Industry Model and Integrated Technology Demonstration of the Karst Plateau-Gorge Rocky Desertification Control (2016YFC0502607); The Key Project of Science and Technology Program of Guizhou Province: Model and Technology demonstration for from the karst desertification control (No.5411 2017 Qiankehe Pingtai Rencai).

\section{REFERENCES}

[1] Agren, G. I. (2004): The C:N:P stoichiometry of autotrophs. Theory and observations. Ecology Letters 7: 185-191.

[2] Cao, G. Y., Cao, Y., Chen, Y. M. (2015): Characteristics of nitrogen and phosphorus stoichiometry across components of forest ecosystem in Shaanxi Province. - Chinese Journal of Plant Ecology 39(12): 1146-1155.

[3] Chen, A. N., Wang, G. J., Chen, C., Li, S. Y., Li, W. J. (2018): Variation in the N and P stoichiometry of leaf-root-soil during stand development in a Cunninghamia lanceolate plantation in subtropical China. - Acta Ecologica Sinica 38(11): 4027-4036.

[4] Cui, G. Y., Cao, Y., Chen, Y. M. (2015): Characteristics of nitrogen and phosphorus stoichiometry across components of forest ecosystem in Shaanxi Province. - Chinese Journal of Plant Ecology 39: 1146-1155.

[5] Dick, W. A., Cheng, L., Wang, P. (2000): Soil acid and alkaline phosphatase activity as PH adjustment indicators. - Soil Biology and Biochemistry 32(13): 1915-1919. 
[6] Du, J. Y., Wang, L. J., Sheng, M. Y., Wen, P. C. (2017): Soil C, N and P stoichiometry of rocky desertification ecosystems in the Karst Plateau Canyon area. - Journal of Sichuan Agricultural University 35(1): 45-51.

[7] Du, M. Y., Fan, S. H., Liu, G. L., Feng, H. Y., Guo, B. H., Tang, X. L. (2016): Stoichiometric characteristics of carbon, nitrogen and phosphorus in Phyllostachys edulis forests of China. - Chinese Journal of Plant Ecology 40(8): 760-774.

[8] Elser, J. J., Fagan, W. F., Denno, R. F., Dobberfuhl, D. R., Folarin, A., Huberty, A., Interlandi, S., Kilham, S. S., McCauley, E., Schulz, K. L., Siemann, E. H., Sterner, R. W. (2000): Nutritional constraints in terrestrial and freshwater food webs. - Nature 408: 578580.

[9] Elser, J. J., Fagan, W. F., Kerkhoff, A. J., Swenson, N. G., Enquist, B. J. (2010): Biological stoichiometry of plant production: Metabolism, scaling and ecological response to global change. - New Phytologist 186: 593-608.

[10] Gusewell, S. (2004): N:P ratios in terrestrial plants: variation and functional significance. - New Phytologist 164: 243-266.

[11] Han, W. X., Fang, J. Y., Guo, D. L., Zhang, Y. (2005): Leaf nitrogen and phosphorus stoichiometry across 753 terrestrial plant species in Chinese. - New Phytologist 168: 377 385.

[12] He, J. S., Fanf, J. Y., Wang, Z. H., Guo, D. L., Flynn, D. F. B., Geng, Z. (2006): Stoichiometry and large-scale patterns of leaf carbon and nitrogen in the grassland biomes of China. - Oecologia 149(1): 115-122.

[13] Hedin, L. O. (2004): Global organization of terrestrial plant-nutrient interactions. Proceedings of the National Academy of Sciences of the United States of America 101: 10849-10850.

[14] Hu, Y. S., Me, X. Y., Liu, Y. H. (2014): N and P stoichiometric traits of plant and soil in different forest succession stages in Changbai Mountains. - Chinese Journal of Applied Ecology 25(3): 632-638.

[15] Jiao, F., Wen, Z. M., An, S. S., Yuan, Z. (2013): Successional changes in soil stoichiometry after land abandonment in Loess Plateau, China. - Ecological Engineering 58: 249-254.

[16] Koerselman, W., Meuleman, A. F. M. (1996): The vegetation N:P ratio: a new tool to detect the nature of nutrient limitation. - Jouranl of Appied Ecology 33(6): 1441-1450.

[17] LeGrand, H. E. (1973): Hydrological and ecological problems of karst regions: hydrological actions on limestone regions cause distinctive ecological problems. Science 179(4076): 859-864.

[18] Leps, J., Smilauer, P. (2003): Multivariate Analysis of Ecological Data Using CANOCO. - Cambridge University Press, Cambridge, UK.

[19] Li, C. J., Xu, X. W., Sun, Y. Q., Qiu, Y. Z., Li, S. Y., Gao, P., Zhong, X. B., Yan, J., Wang, G. F. (2014): Stoichiometric characteristics of C, N, P for three desert plants leaf and soil at different habitats. - Arid Land Geography 37(5): 996-1004.

[20] Li, Y. Q., Huang, Y. Q., Xu, G. P., Sun, Y. J., Zhang, Z. F., He, C. X., Huang, K. C., He, W. (2018): Characteristics of soil nutrients and microbial activities of reed vegetation in the Huixian karst wetland, Guilin, China. - Chinese Journal of Ecology 37(1): 64-74.

[21] Long, J., Huang, C. Y., Li, J. (2002): Effects of land use on soil quality in karst hilly area. - Journal of Soil and Water Conservation 16(1): 76-79.

[22] Minden, V., Kleyer, M. (2014): Internal and external regulation of plant organ stoichiometry. - Plant Biology 16: 897-907.

[23] Pena-Claros, M. (2003): Changes in forest structure and species composition during secondary forest succession in the Bolivian Amazon. - Biotropica 35: 450-461.

[24] Reich, P. B. (2003): The evolution of plant functional variation: traits, spectra and strategies. - International Journal of Plant Sciences 164: 143-164. 
[25] Reich, P. B., Oleksyn, J. (2004): Global patterns of plant leaf N and P in relation to temperature and latitude. - Proceedings of the National Academy of Sciences of the United States of America 101: 11001-11006.

[26] Sheng, M. Y., Liu, Y., Xiong, K. N. (2013): Response of soil physical-chemical properties to rocky desertification succession in South China Karst. - Acta Ecologica Sinica 33(19): 6303-6313.

[27] Sheng, M. Y., Xiong, K. N., Cui, G. Y., Liu, Y. (2015): Plant diversity and soil physicalchemical properties in karst rocky desertification ecosystem of Guizhou, China. - Acta Ecologica Sinica 35(2): 434-448.

[28] Sterner, R. W., Elser, J. J. (2002): Ecological Stoichiometry: The Biology of Elements from Molecules to the Biosphere. - Princeton University Press, Princeton.

[29] Tessier, J. T., Raynal, D. J. (2003): Use of nitrogen to phosphorus ratios in plant tissue as an indicator of nutrient limitation and nitrogen asturation. - Journal of Applied Ecology 40: 523-534.

[30] Tian, H. Q., Chen, G. S., Zhang, C., Melillo, J. M., Hall, C. A. S. (2010): Patterm and variation of $\mathrm{C}: \mathrm{N}: \mathrm{P}$ ratios in China's soils: a synthesis of observational data. Biogeochemistry 98(1/3): 139-151.

[31] Tian, J., Sheng, M. Y., Wang, P., Wen, P. C. (2019): Influence of land use change on litter and soil $\mathrm{C}, \mathrm{N}, \mathrm{P}$ stoichiometric characteristics and soil enzyme activity in karst ecosystem, Southwest China. - Environmental Science 40(9): 4278-4286.

[32] Wang, J. Y., Wang, S. Q., Li, R. L., Yan, J. H., Sha, L. Q., Han, S. J. (2011): Leaf stoichiometry of trees in three forest types in Pearl River Delta, South China. - Chinese Journal of Plant Ecology 35(6): 587-595.

[33] Wang, K. L., Yue, Y. M., Ma, Z. L., Lei, T. W., Li, D. J., Song, T. Q. (2016a): Research and demonstration on technologies for rocky desertification treatment and ecosystem service enhancement in karst peak-cluster depression regions. - Acta Ecologica Sinica 36(22): 7098-7102.

[34] Wang, M. C., Zhang, X. C., Li, H. J., Zhou, H. Y., Wei, X. H., Guan, G. C. (2016b): An analysis of soil quality changes in the process of ecological restoration in karst rocky desertification area: a case study in karst ecological restoration and rehabilitation region of Guzhou Village. - Ecology and Environmental Sciences 25(6): 947-955.

[35] Wang, W. Q., Xu, L. L., Zeng, C. S., Tong, C., Zhang, L. H. (2011): Carbon, nitrogen and phosphorus ecological stoichiometric ratios among live plant-litter-soil systems in estuarine wetland. - Acta Ecologica Sinica 31(23): 134-139.

[36] Wu, T. G., Chen, B. F., Xiao, Y. H., Pan, Y. J., Chen, Y., Xiao, J. H. (2010): Leaf stoichiometry of trees in three forest types in Pearl River Delta, South China. - Chinese Journal of Plant Ecology 34(1): 58-63.

[37] Xiang, Y., Cheng, M., An, S. S., Zeng, Q. C. (2015): Soil-plant-litter stoichiometry under different site conditions in Yanhe Catchment, China. - Journal of Natural Resource 30(10): 1642-1652.

[38] Xiong, K. N., Chen, Y. B., Chen, H. (2011): Gold Formation from Points of Stone. Technology and Model of Stone Desertification Control in Guizhou Province. - Guizhou Science and Technology Publishing House, Guiyang, China.

[39] Xiong, K. N., Zhu, D. Y., Peng, T., Yu, L. F., Xue, J. H., Li, P. (2016): Study on Ecological industry technology and demonstration for Karst rocky desertification control of the Karst Plateau-Gorge. - Acta Ecologica Sinica 36(22): 7109-7113.

[40] Xu, Z. G., He, Y., Yan, B. X., Song. C. C. (2006): Effects of plant N/P and Soil pH on species richness of wetland plants. - China Environmental Science 3: 346-349.

[41] Yang, C. J., Zeng, J., Xu, D. P., Li, S. J., Lu, J. (2007): The processes and dominant factors of forest litter decomposition: a review. - Ecology and Environmental Sciences 16(2): 649-654.

[42] Yang, S. T., Zhu, Q. J. (2000): The rate of environmental degradation and natural rehabilitation in typical karst area of Guizhou. - Acta Geographica Sinica 55(4): 459-466. 
[43] Zeng, Z. X., Wang, K. L., Liu, X. L., Zeng, F. P., Song, T. Q., Peng, W. X., Zhang, H., $\mathrm{Du}, \mathrm{H}$. (2015): Stoichiometric characteristics of plants, litter and soils in karst plant communities of Northwest Guangxi. - Chinese Journal of Plant Ecology 39(7): 682-693.

[44] Zhao, F. Z., Sun, J., Ren, C. J., Kang, D., Deng, J., Han, X. H., Yang, G. H., Feng, Y. Z., Ren, G. X. (2015): Land use change influences soil C, N, and P stoichiometry under 'Grain-to-Green Program' in China. - Scientific Reports 5: 10195.

[45] Zhao, W. J., Liu, X. D., Jin, M., Zhang, X. L., Che, Z. S., Jing, W. M., Wang, S. L., Niu, Y., Qi, P., Li, J. W. (2016): Ecological stoichiometric characteristics of carbon, nitrogen and phosphorus in leaf-litter-soil system of picea crassifolia forest in the Qilian Mountains. - Acta Pedologica Sinica 53(2): 477-489.

[46] Zhao, W. J., Li, Q., Cui, Y. C., Hou, Y. J., Yang, B., Ding, F. J., Wu, P. (2019): Effects on nutrient content and stoichiometric characteristics during rocky desertification control in karst region: a case study of Gangzhai small watershed of central Guizhou Province. Journal of Central South University of Forestry \& Technology 39(8): 76-86.

[47] Zheng, J. Y., Shao, M. A., Zhang, X. C. (2004): Spatial variation of surface soil's bulk density and saturated hydraulic conductivity on slope in loess region. - Journal of Soil and Water Conservation 18(3): 53-56.

[48] Zhong, Q. L., Liu, L. B., Xu, X., Yang, Y., Guo, Y. M., Xu, H. Y., Cai, X. L., Ni, J. (2018): Variations of plant functional traits and adaptive strategy of woody species in a karst forest of central Guizhou Province, southwestern China. - Chinese Journal of Plant Ecology 42(5): 562-572.

[49] Zhu, Q. L., Xing, X. Y., Zhang, H., An, S. S. (2013): Soil ecological stoichiometry under different vegetation area on loess hillygully region. - Acta Ecologica Sinica 33(15): 4674-4682. 